\title{
Prognostic value and management of regional lymph nodes in locoregional breast cancer recurrence: a systematic review of the literature
}

\author{
Isabell Ge $\mathrm{e}^{1,2} \cdot$ Thalia Erbes $^{1,2} \cdot$ Ingolf Juhasz-Böss ${ }^{1,2}$ \\ Received: 30 August 2021 / Accepted: 24 November 2021 / Published online: 4 February 2022 \\ (c) The Author(s) 2022
}

\begin{abstract}
Purpose Management of regional lymph nodes in breast cancer recurrence has been heterogeneous. To facilitate clinical practice, this review aims to give an overview on the prognosis, staging and operative management of (inapparent) regional lymph nodes.

Methods Current national and international guidelines are reviewed and a structured search of the literature between Jan 1, 1999 and Feb 1, 2021 on the repeat sentinel node biopsy (re-SNB) procedure was performed.

Results Positive regional lymph nodes in recurrent breast cancer indicate a poorer outcome with axillary recurrences being the most favorable tumor site among all nodal regions. Most preferred staging method is ultrasound \pm guided biopsy. PETCT, scintimammography, SPECT-CT may improve visualization of affected lymph nodes outside the axilla. Concerning operative management 30 articles on re-SNB were identified with a mean harvesting rate of $66.4 \%$, aberrant drainage and aberrant metastasis in $1 / 3$ of the cases. Total rate of metastasis is $17.9 \%$. After previous axillary dissection (ALND) the re-SNB has a significantly lower harvesting rate and higher aberrant drainage and aberrant metastasis rate. The prognostic outcome after re-SNB has been favorable.

Conclusion Nodal status in recurrent disease has prognostic value. The choice of operative management of clinically inapparent regional lymph nodes during local recurrence should be based on the previous nodal staging method. Patients with previous ALND should be spared a second systematic ALND. Re-SNB or no axillary surgery at all are possible alternatives. Lymphoscintigraphy may be performed to identify extraaxillary drainage. However, for definite recommendations randomized controlled studies are heavily needed.
\end{abstract}

Keywords Breast cancer recurrence $\cdot$ Nodal status $\cdot$ Radiologic diagnosis $\cdot$ Prognosis $\cdot$ Repeat sentinel node biopsy $\cdot$ Aberrant drainage

\section{Introduction}

Breast Cancer is a common oncological disease characterized by a favorable prognosis due to its early detection and multimodal treatment options. Although the diagnostics and therapy of early breast cancer is standardized, there is a more challenging task with recurrent disease. Therapy

Isabell Ge

isabell_ge@yahoo.de; isabellxiang.ge@usb.ch

1 Department of Obstetrics and Gynecology, Medical Center University of Freiburg, Freiburg, Germany

2 Faculty of Medicine, University of Freiburg, Freiburg, Germany options during breast cancer relapse are diverse and may vary depending on a cancer institute's individual beliefs and experience. This is especially evident in the management of clinically negative lymph nodes during the reoperation. There is the possibility to perform an axillary node dissection (ALND), a (re-)sentinel node biopsy (SNB), nodal sampling or to not do anything at all. Due to the heterogeneity, we try to find answers to the following three central questions on the management of lymph nodes in recurrent breast cancer:

1. Which prognostic role does the lymph node status play in recurrent breast cancer?

2. What are useful staging methods for lymph node involvement? 
3. Which surgical approach should be chosen with clinically negative lymph nodes?

With this review, we aim to give an overview of the extensive literature which might facilitate the clinical practice on recurrent breast cancer disease.

\section{Materials and methods}

To assess the current recommended standard of care for breast cancer relapse, we studied the following national and international guidelines and recommendations:

- the German interdisciplinary S3-guideline on "Screening, diagnostic, therapy, follow-up-care of breast cancer (Früherkennung, Diagnostik, Therapie und Nachsorge des Mammakarzinoms), extended version 4.3, Feb, 2020"

- the recommendations of AGO, the German gynecologiconcologic working group on "Loco-regional Recurrence", version March, 2021.

- American NCCN guidelines Version 1.2021 Breast Cancer
Furthermore, we conducted a structured search of the literature in PubMed using Medical Subject Headings (MeSH) and textwords. The search was conducted on Feb 1, 2021 and limited to studies published between Jan 1, 1999 and Feb 1, 2021. For details of the search strategy, see Fig. 1 and supplementary document 1 .

We conducted a review of the literature on the feasibility and outcome of a Re-SNB in recurrent disease. For statistical analysis, descriptive statistics (percentage, mean, range) and $t$ tests were performed.

\section{Results}

\section{Prognostic role of lymph node status in recurrent disease}

There are few known prognostic factors which may predict the disease progression and survival after breast cancer recurrence. The German S3-Guideline include a positive nodal status at primary diagnosis but not at recurrent disease as a poor prognostic factor. Lymphovascular space invasion is considered a poor prognostic factor for a second recurrence according to the AGO recommendations.
Fig. 1 Flowchart of search strategy for systematic review
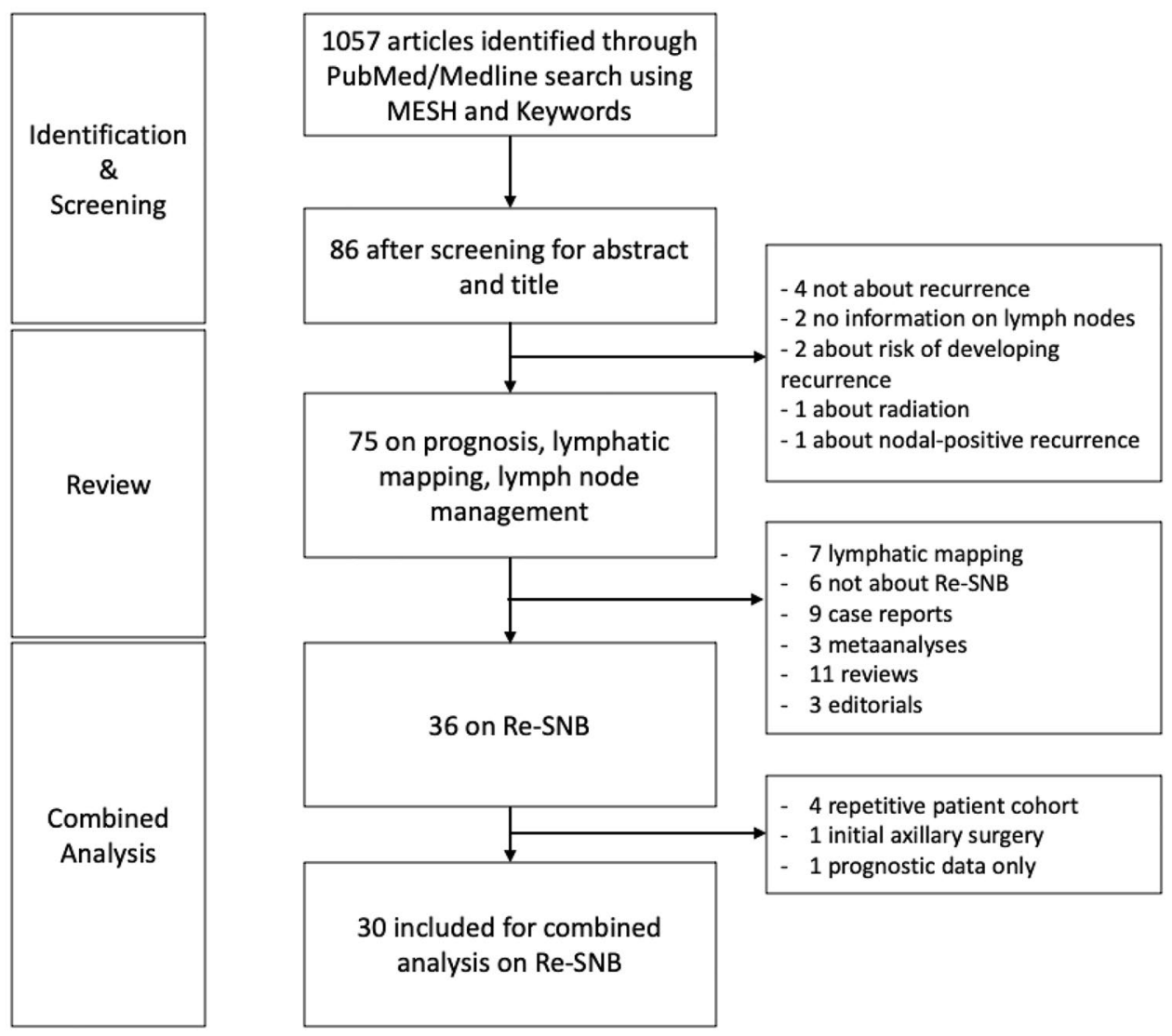
After exploring the literature on the prognostic role of nodal stage in recurrent disease, we identified articles which compared ipsilateral local breast tissue recurrence without lymph node or distant metastases (IBTR) to regional recurrence with lymphonodal involvement.

\section{Overall, disease-free and distant disease-free survival}

Compared to IBTR, regional recurrence in the lymph nodes is associated with worse overall, disease-free and distant disease-free survival. Anderson and al. analyzed 419 patients with recurrent disease, of which 342 patients had an IBTR and 77 patients had a locoregional recurrence either in the regional lymph nodes, chest wall or nonbreast skin. The 5-year overall survival and distant disease-free survival after a locoregional recurrence (34.9 and $27.8 \%$, respectively) was considerably worse than after an IBTR (76.6 and $67.1 \%$, respectively) irrespective of the initial therapy [1]. Another study by Harris et al. showed that the 5- and 10-year overall survival rates for patients with a regional lymph node recurrence (72 and $43 \%$, respectively) was lower than for patients without any regional lymph node recurrence (91 and $81 \%$, respectively) [2]. Montagna et al. analysed 197 patients with local recurrence in the ipsilateral breast or chest wall and 82 patients with regional lymphonodal recurrence with a median follow-up of 5.9 years and found a significantly higher risk of distant metastasis for patients with regional lymphonodal recurrence occuring more than 2 years after the primary diagnosis (Hazard ratio $[\mathrm{HR}]=2.76 ; 95 \%$ CI 1.31-5.85) [3]. Lee et al. showed similar results. In 104 patients with ipsilateral locoregional recurrence, 35 patients (33.7\%) had a regional lymph node recurrence. Compared to recurrent disease limited to the breast or chest wall, recurrent disease in regional lymph nodes was identified as an independent and significant prognostic factor for distant metastasis during a median follow-up of 8.9 years (HR of 2.816 (95\% CI: 1.342-5.908, $p: 0.006)$ ) [4].

Interestingly, the impact of locoregional recurrence on survival seems to vary depending on the breast cancer subtype. Anderson et al. showed that patients with Estrogen-receptor(ER)-negative regional recurrence in the regional lymph nodes, chest wall or non-breast skin had a HR for mortality of 19.84 (95\% CI: 13.33-29.54) compared to patients with ER-negative IBTR with a HR of 4.49 (3.29-6.13) [1]. In the study of Montagna et al., triple-negative disease in locoregional recurrence was associated with a higher risk of a subsequent relapse (HR 2.87 [1.67-4.91]) and death (HR 2.00 [1.25-3.19]) compared to other breast cancer subtypes.

\section{Axillary lymph node recurrence}

Although the results above seem consistent, their interpretation still poses difficulties. In many studies regional disease is summarized as multiple tumor localizations without the separate analysis of a single recurrence localization, e.g., the axillary lymph nodes, the most common nodal relapse site. In the study of Montagna et al. regional recurrence is defined as cancer in the axillary, internal mammary, supraclavicular or infraclavicular lymph nodes [3]. Lee et al. and Anderson et al. additionally count cervical lymph nodes and ipsilateral chest wall/non breast skin, respectively, to regional disease $[1,4]$.

In one study by Harris et al. isolated axillary lymph node recurrence were analyzed in comparison to other localizations. The author reports that over $50 \%$ of regional recurrence occurred in the axilla only. Axillary recurrence was shown as a favorable prognostic factor $(p=0.004)$ as it was associated with better overall, cause-specific and distant disease-free survival [2]. Similar results were reported in older studies by Fowble et al. and Recht et al. demonstrating that axillary lymph nodes were the most favorable recurrent site in terms of prognosis compared to other regional lymph nodes [5, 6]. In a study of the National Surgical Adjuvant Breast and Bowel Project (NSABP) trial, 424 patients with recurrent breast cancer and initially node-positive disease were analyzed, with 259 patients having a IBTR and 165 having a regional recurrence in the lymph nodes, chest wall or nonbreast skin. Patients with recurrence in the axillary nodes showed a higher 5-year distant disease-free survival rate $(31.5 \%)$ compared to patients with supraclavicular metastasis $(12.1 \%)$, but a lower disease-free survival rate compared to patients with IBTR (51.4\%) [7].

\section{Staging methods for lymph node involvement in recurrent breast cancer}

\section{Ultrasound \pm guided biopsy}

In general, the most preferred screening and detection method for axillary lymph node metastases is an ultrasound followed by an ultrasound-guided biopsy.

According to a pooled analysis which included 9.232 cases of axillary staging procedures, $50 \%$ of axillary metastases were detected by an axillary ultrasound \pm biopsy with a false-negative rate of $25 \%$ [8]. Another metanalysis with 31 publications found a higher accuracy for detection of axillary node involvement: a pooled sensitivity and specificity of 61.4 and $82 \%$ with ultrasound alone and 79.6 and $98.3 \%$ with the addition of ultrasound-guided biopsy [9]. Median positive predictive value (PPV) and negative predictive value (NPV) for the biopsy were estimated as 100 and $67.4 \%$, respectively. According to Schipper et al. axillary 
ultrasound could detect advanced axillary disease (pN2pN3) with a NPV of up to $97.7 \%$, but could not accurately predict the difference between $\mathrm{pN} 1$ and $\mathrm{pN} 2-\mathrm{pN} 3$ disease [10].

Likewise, in recurrent breast cancer disease, ultrasound has been deemed useful in the detection of axillary and supraclavicular lymph node recurrences with a sensitivity, specificity and NPV of 76.9, 98.7 and 99.5\%, respectively [11].

\section{Magnetic resonance imaging (MRI)}

In routine diagnostics, breast MRI can add supplementary information on the evaluation of locoregional tumor extent as well as the differentiation between scarring and recurrent lesions. In terms of nodal disease, mean sensitivity and specificity was $90 \%$ according to a meta-analysis which included 309 patients. MRIs enhanced with ultrasmall superparamagnetic iron oxide performed slightly better with a mean sensitivity and specificity of 98 and $96 \%$, respectively [12]. When comparing MRI to an axillary ultrasound, the NPV for the detection of advanced axillary disease was slightly higher for MRI (99.3 vs. $98.5 \%)$. In addition, the differentiation between $\mathrm{pN} 1$ and $\mathrm{pN} 2-\mathrm{pN} 3$ disease was more accurate by MRI, which leads to the conclusion that axillary ultrasound may be omitted in case the breast-MRI shows no pathological nodal findings [13].

\section{Computer tomography (CT)}

A CT scan is routinely performed as a staging tool for distant metastases. Although it is not primarily designated for nodal surveillance, lymph node recurrences can be detected using CT imaging. DeSelm et al. mapped the anatomic pattern of isolated nodal recurrences with axial CT scans and identified the axilla as the most frequent site of nodal recurrence with $42 \%$. Other regional recurrence sites include the internal mammary and the supraclavicular region with 32.5 and $25.5 \%$, respectively [14]. In recurrent disease, Abi-Sheisha et al. showed that CT could detect lymph node metastases $>1 \mathrm{~cm}$ easily, but might be inferior to PET-CT in the detection of smaller and extra-axillary nodal recurrences [15].

\section{Fluordesoxyglucose Positron-Emission Tomography (FDG-) PET-CT}

PET-CT is usually not included in routine breast cancer staging, though it might be helpful when an area of interest is not furtherly accessible by conventional imaging or biopsy.

For the general detection of axillary lymph node involvement at primary disease, PET-CT might be inferior to conventional imaging with a sensitivity up to $70 \%$ compared to $85.7 \%$. However, it has a high specificity with up to $100 \%$.
Furthermore, PET-CT proves itself superior to conventional methods when detecting extra-axillary lymph node involvement $[16,17]$. This feature might especially be useful at breast cancer relapse, as PET-CT has displayed a higher distribution of metastases in the internal mammary and supraclavicular region than at primary disease [18]. In recurrent setting, PET-CT showed much higher detection rates for axillary and extra-axillary lymph node involvements compared to CT and whole-body MRI with a diagnostic accuracy of up to 98.7 vs. $77.5 \%$ and $75 \%$, respectively $[19,20]$.

\section{Scintimammography}

Scintimammographies are performed using the injection of radioactive tracers (e.g., Technetium- $99 \mathrm{~m}$ sestamibi) in the opposite arm of the suspected cancer lesion. After 5-10 min, planar scintigraphs are taken with a gamma camera which visualizes the thoracal field including the breast, chest wall and axillary region. This method is not recommended in routine breast cancer screening and staging but can be performed supplementary in selected cases, such as in patients with dense breast tissue or palpable masses without mammographic or sonographic findings.

For axillary staging, scintimammography (sensitivity: 64\%, specificity: 90\%) performed better than mammography but worse than ultrasound (sensitivity: $73 \%$, specificity: 95\%) [21]. In recurrent setting though, the sensitivity of scintimammographies in detecting regional lymph node metastases was much higher with $93 \%$ [22].

\section{Operative staging, lymphoscintigraphy, SPECT/CT}

Several studies have shown that an operative staging via sentinel lymph node biopsy has a higher sensitivity in detecting lymph node metastases compared to PET or MRI [12, 23]. Sentinel lymph nodes are usually localized using blue-dye or, nowadays more commonly, radiocolloid infection and a planar lymphoscintigraphy. In case the visualization fails, a SPECT/CT may be added. In a study with 134 patients, SPECT/CT discovered 19 additional sentinel lymph nodes in 15 patients including 4 nodal metastases which otherwise would have been missed. An additional advantage of SPECT/CT was estimated in $42 \%$ of the patients through improved localization and more precise operative incision [24]. Another study with 741 patients showed that SPECT/CT was able to detect $97.8 \%$ of sentinels and was not restricted to Level I of the axillary region only but localized sentinels in Level II, III, the internal mammary chain and supraclavicular region [25]. Borelli et al. analyzed the role of SPECT/CT in breast cancer relapse. Compared to planar lymphoscintigraphy, SPECT/CT showed a slightly higher visualization rate of sentinel nodes (53.3 vs. $43.4 \%$, nonsignificant) with 
19 additionally detected nodes. Except for one case, all nodal metastases were found in basins outside the ipsilateral axilla.

\section{Surgical management of clinically negative lymph nodes in recurrent disease}

\section{Guidelines and recommendations}

After previous ALND, both the German S3 Guideline and AGO recommendations don't recommend any axillary intervention in case of clinically negative lymph nodes.

For women who underwent previous SNB, the consensus recommendation of the NCCN is the performance of an ALND of Level I and II. A Re-SNB should be avoided after previous mastectomy, since its prognostic significance is unknown, but may be considered after previous lumpectomy. The German AGO recommendation classifies a re-SNB as a potential "disadvantage for patients" and that "it might not be performed". In case the re-SNB procedure is performed nevertheless but no sentinel lymph node is detected, an ALND as well as an operative intervention outside the ipsilateral axilla should not be performed.

\section{Literature research, summarized results}

After extensive literature research we identified 30 articles with 1945 cases on the feasibility and outcome of the ReSNB procedure in recurrent disease. There were 5 articles analyzing patients with previous sentinel node biopsy only, 2 on previous ALND only, 14 on breast-conserving therapy only and 1 on mastectomy only. 13 articles analyzed patients with mixed characteristics. All identified literature is listed in Table 1. Its combined results are summarized in Table 2.

\section{Success of re-sentinel node biopsy}

The mean harvesting rate of re-sentinel nodes was $66.4 \%$ (1291/1945). The success was significantly higher in patients with previous SNB (79.8\%, range: 38.5-100\%) compared to patients with previous ALND (49.0\%, range: $29-100 \%$, $p=0.009)$. When comparing previous breast-conserving surgery (BCS) and mastectomy (ME), the sentinel node harvesting rate was similar $(66.5 \%$ (1059/1593) vs. 64.2 $(86 / 134), p=0.29)$; however, it should be noted, that far less cases with previous mastectomy were investigated. When collectively evaluating the previous operative procedure of breast and axilla, the combination of initial BCS and SNB yielded the best success rates for re-SNB at recurrence [26, 27].

\section{Aberrant drainage}

Re-SNB was performed using a Technetium-99 m-based radiocolloid, blue dye or both. In one case, indocyanine green (ICG) fluorescence was added when the conventional method failed and identified additional nodes [28]. Lymphatic drainage was visualized by preoperative lymphoscintigraphy or located intraoperatively using a gamma probe. Aberrant drainage was seen in $32.6 \%$ of cases, with a significantly higher rate after previous ALND $(81,8 \%)$ compared to previous SNB $(16.5 \%, p<0.001)$. Most common regional drainage sites outside the ipsilateral axilla were: internal mammary, supra-/infraclaviculary and interpectoral region as well as the contralateral axilla. Aside from axillary dissection, previous radiation seemed to influence the drainage pattern as well. In two studies all patients with lymphatic drainage to the contralateral axilla had a history of radiation during primary disease [29, 30].

\section{Metastases}

Lymph node metastases were found in 218 out of 1220 cases $(17.9 \%)$. In articles which specified metastatic sites, a third were found in aberrant basins (33.7\%). Patients with previous ALND were more likely to have positive nodes outside the ipsilateral axilla than patients with previous SNB (64.3 vs. $13.1 \%, p<0.001)$. Most common aberrant metastatic sites were the internal mammary and contralateral axillary region.

\section{Operative management}

When a positive macrometastatic sentinel node was detected, a complementary-sometimes contralateralALND or axillary exploration was performed. In few cases, when the positive node was found in the internal mammary region only, no additional axillary operation was performed [31-33]. Similarly, the detection of micrometastases or isolated tumor cells (ITC) were usually not followed by ALND with few exceptions [26, 34].

When a negative sentinel node was found. a ALND was usually considered unnecessary. However, many studies including the SNARB-study with the largest number of cases $(n=536)$ performed back-up ALNDs to evaluate the false-negative rate of the re-SNB procedure [31, 35-38]. According to a meta-analysis which included 170 patients with back-up ALND after negative re-SNB, the overall falsenegative rate was low $(9.4 \%)$. The sensitivity, negative predictive value and the accuracy of the re-SNB procedure were $90,6 \%, 95,9 \%$ and $97,1 \%$, respectively [39].

When a sentinel node was not visualized or detected, the operative management was heterogenous across all studies. Some studies performed ALND in all patients with 


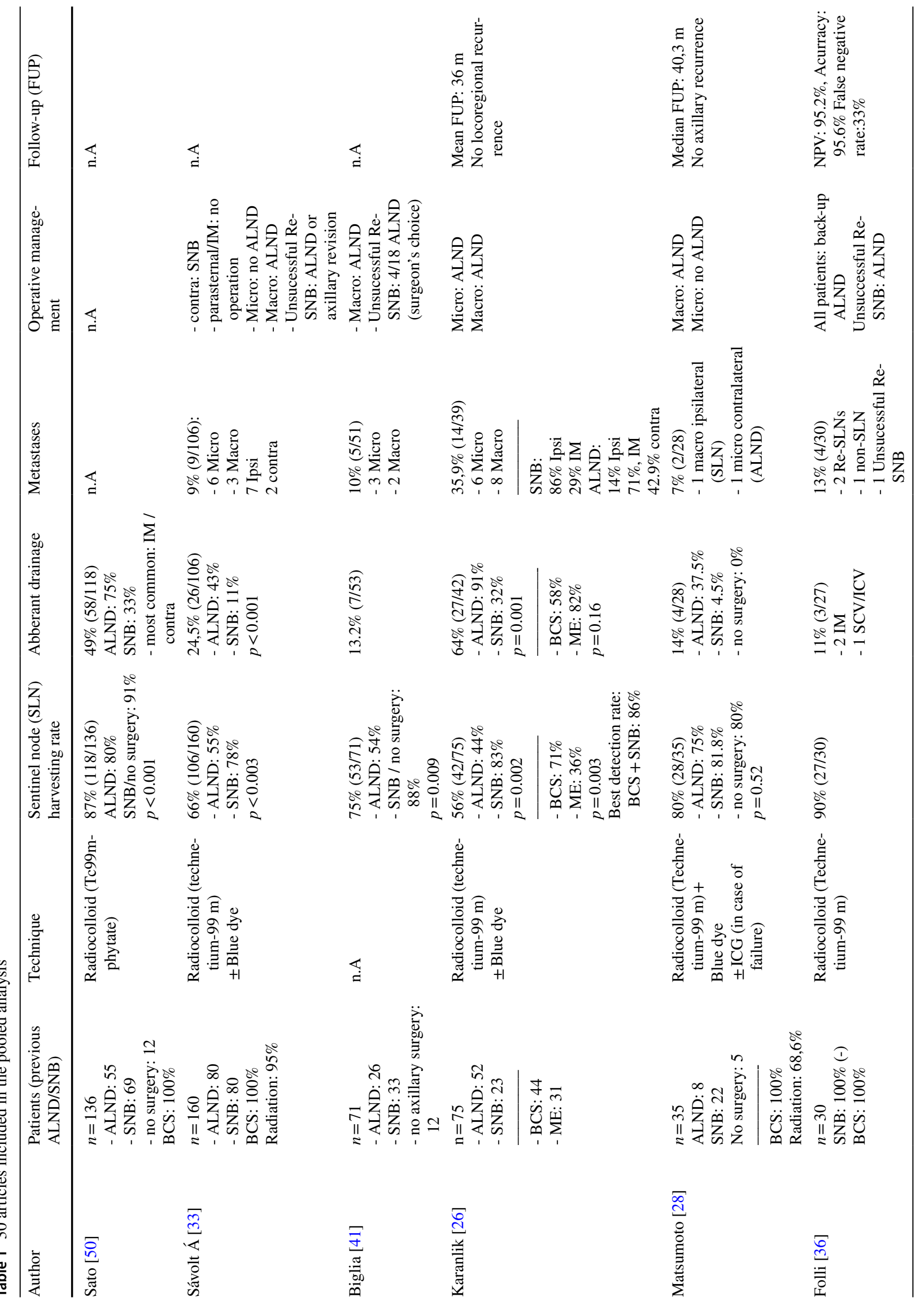




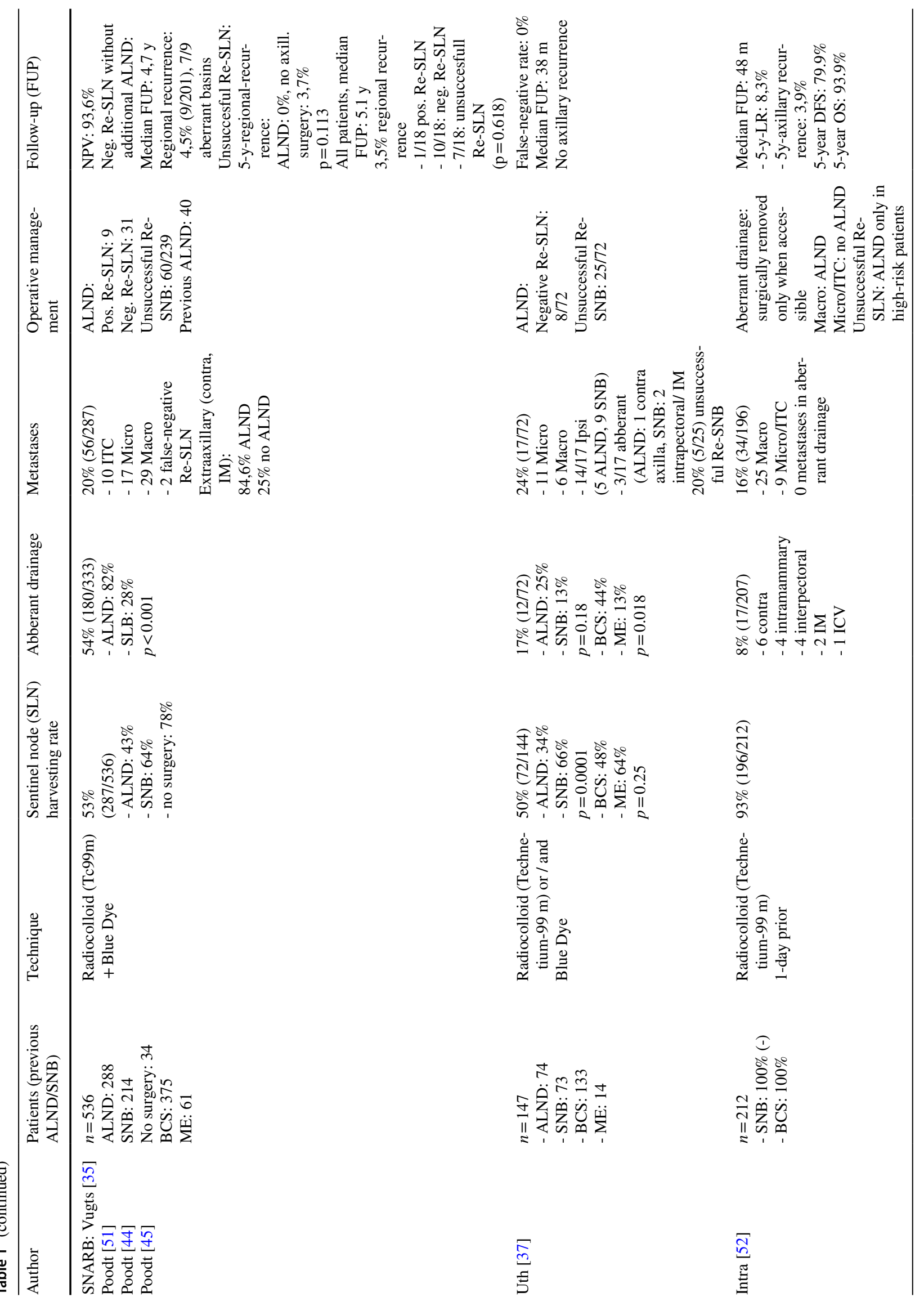




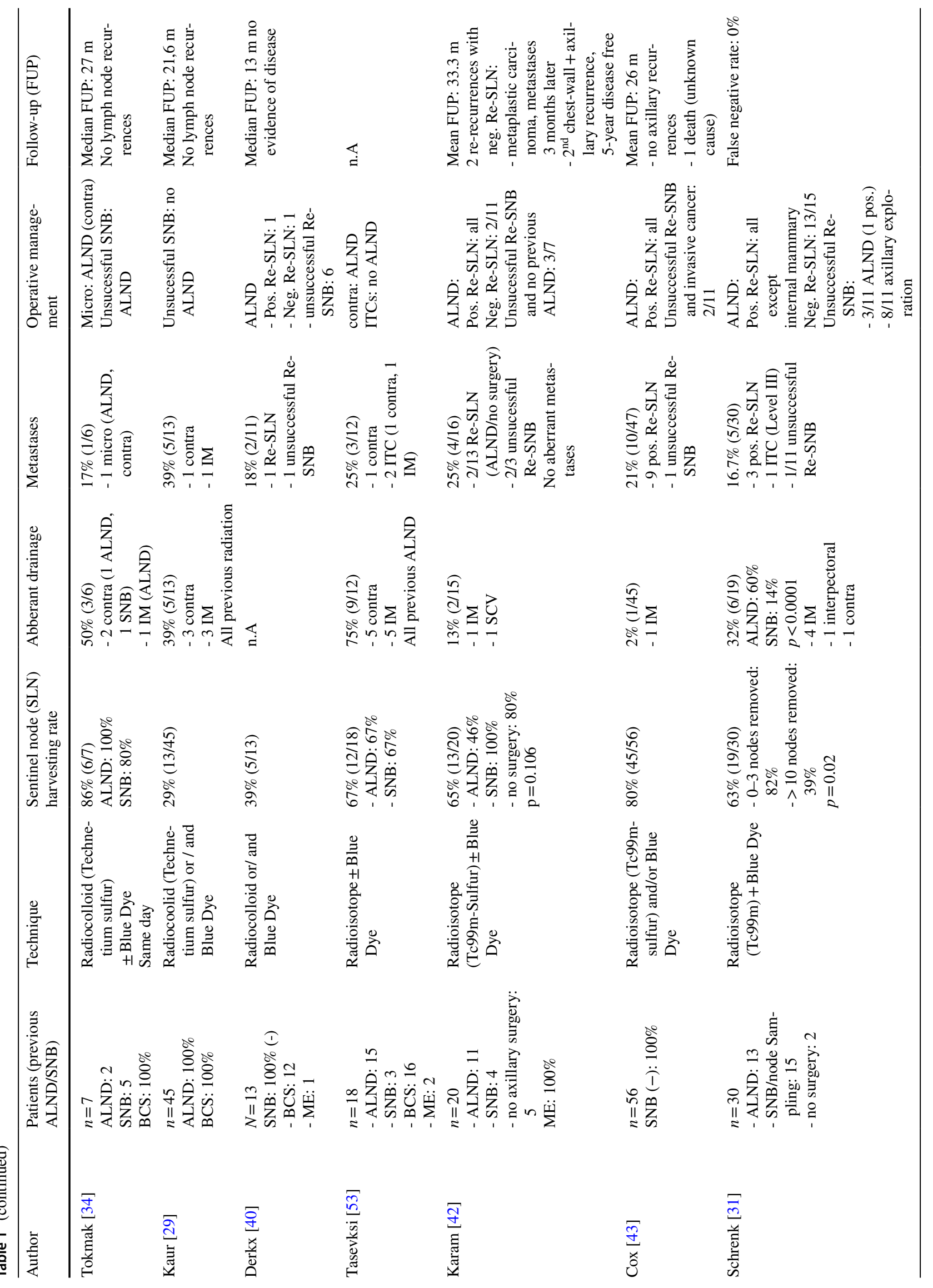




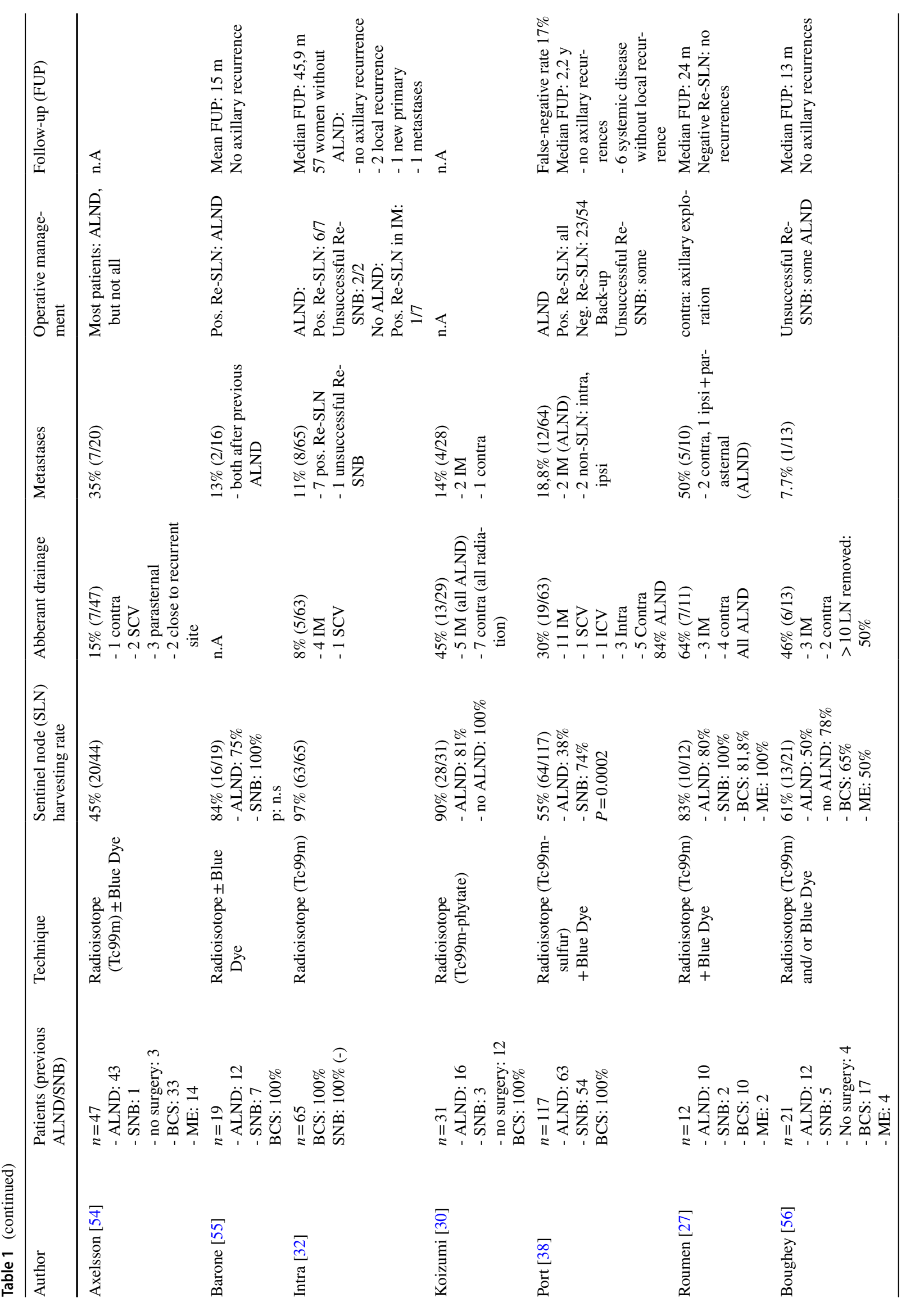




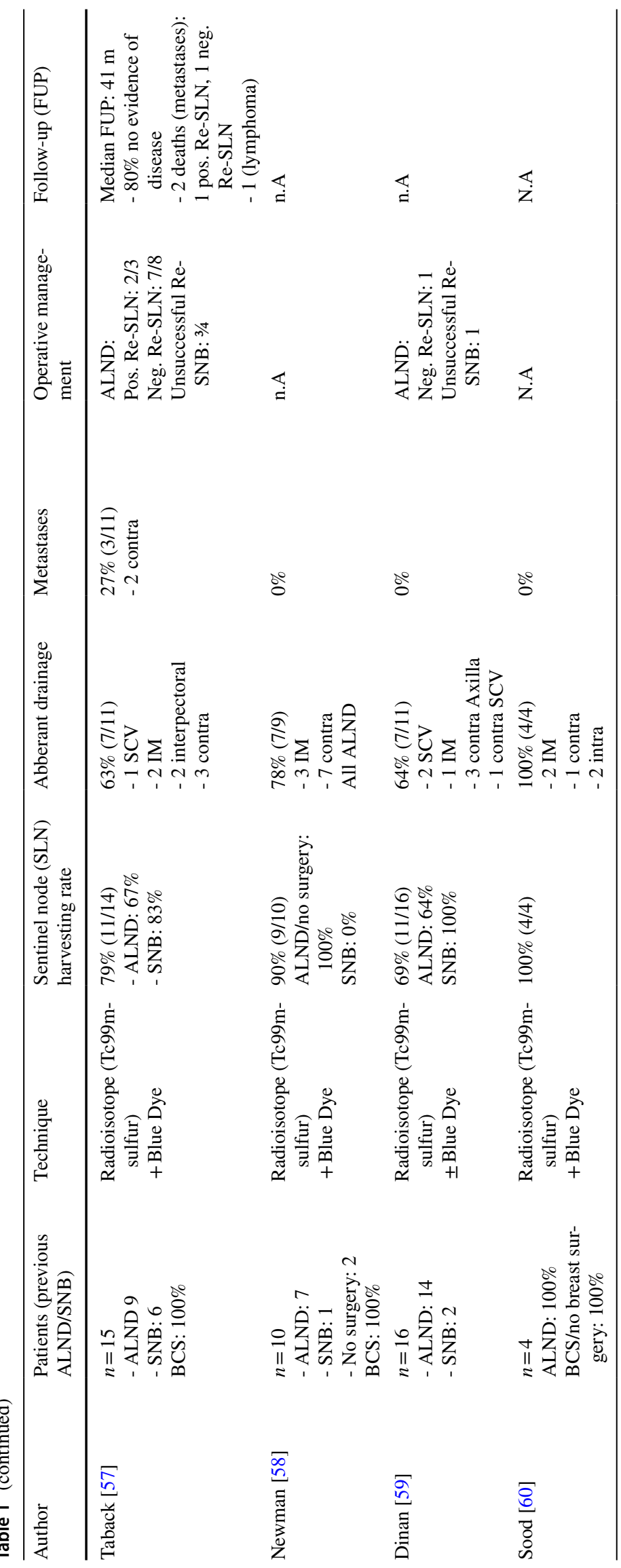


Table 2 Summarized results of 30 articles

\begin{tabular}{llllr}
\hline & Total & Previous SNB & Previous ALND & $p$ value \\
\hline Sentinel node harvesting rate & $66.4 \%(1291 / 1945)$ & $79.8 \%(693 / 869)$ & $49.0 \%(400 / 816)$ & 0.009 \\
Aberrant drainage & $32.6 \%(442 / 1357)$ & $16.5 \%(120 / 726)$ & $81.8 \%(318 / 389)$ & $<0.001$ \\
Aberrant metastasis & $33.7 \%(58 / 171)$ & $13.1 \%(11 / 84)$ & $64.3 \%(45 / 70)$ & $<0.001$ \\
Total metastasis & $17.9 \%(218 / 1220)$ & & & \\
\hline
\end{tabular}

unsuccessful re-SNB [31, 33, 34, 36, 40], others left the decision to the surgeon $[38,41]$. In some cases, an ALND was performed depending on the previous axillary operation [35, 42]. Kaur et al. did not perform ALND at all, as all patients had previous ALND at primary disease [29]. Intra et al. performed ALND in high-risk patients and Cox et al. in patients with invasive recurrent disease [32, 43]. Uth et al. did not specify their reason for performing or omitting an ALND, but found metastases in $20 \%$ (5/25) of patients with ALND after unsuccessful SNB.

\section{Outcome and prognosis}

The prognosis after Re-Sentinel biopsy has been favorable. In many studies which omitted an ALND in case of negative Re-sentinels, no axillary recurrence has been observed after a median follow-up time up of 27 months (range: 15-46,9 months). (Karanlik, Matsumoto, Tokmak, Kaur, Cox, Barone, Intra, Roumen).

As the largest study on Re-SNB, the SNARB-study furtherly explored its prognostic value. After a median follow-up of 5.1 years, regional recurrence was observed in 18 patients (3.5\%). 1 out of 18 patients had a positive Resentinel node, 10 had a negative Re-sentinel node und 7 had unsuccessful Re-SNB. Distant recurrences occurred in 88 patients (17.1\%). The 5-year distant disease-free survival in the patients with negative, positive and unsuccessful re-SNB was comparable with $85.4,76$ and $84.7 \%$, respectively. In conclusion, the SNARB-study found no significant association between the outcome of Re-SNB and the occurrence of regional $(p=0.618)$ and distant recurrence $(p=0.682)$ [44]. Moreover, according to their results, an ALND after an unsuccessful Re-SNB may be omitted, as the risk of developing a regional recurrence is negligible irrespective of a followed ALND (5-year regional recurrence rate: $0 \%$ for ALND vs. $3.7 \%$ for no surgery, $p=0.113$ ) [45]. However, it has been noted that when additionally considering the initial axillary operation, the majority of the unsuccessful Re-SNB group had an ALND, either at prior disease or at recurrence. Ultimately out of 239 cases with unsuccessful Re-SNB, only 26 patients were spared an ALND [46]. The low number of cases makes the validity of the results questionable.

In contrast to the SNARB study, prior axillary staging method did not matter in a study by Ugras et al. In this study, all patients with an ipsilateral breast or chest wall recurrence had a previous negative SNB. Out of 83 patients which were included, 47 were treated with a re-SNB and 36 without axillary surgery. The outcome after a median follow-up of 4.2 years was comparable between both groups. Axillary and non-axillary recurrence as well as death rate were low with $2.6,5.5 \%$ and $3.9 \%$, respectively. Distant metastasis occurred in 8 patients $(12.5 \%)$ with 5 in the re-SNB and 3 in the non-surgery group. Thus, this study demonstrates the feasibility of the Re-SNB procedure but questions its worth and value [47].

\section{Discussion}

\section{Prognostic role of nodal status in recurrent breast cancer disease}

Although the guidelines don't explicitly list nodal status in recurrent disease as a prognostic factor, there is evidence that a positive nodal involvement might be associated with poorer survival. Axillary node recurrences seem to have a worse prognosis compared to local ipsilateral breast disease but are a more favorable tumor site compared to other nodal regions.

\section{Staging methods for lymph node involvement}

The most preferred imaging method for detection of lymph node metastases is an ultrasound \pm ultrasound-guided biopsy. This method is fast, cost-effective, uses no radiation and has a high sensitivity and specificity at primary disease and at recurrence. An MRI might be supplementary added. CTs, though not intended for nodal screening specifically, might detect enlarged lymph nodes during routine staging for distant metastasis.

In recurrent disease, lymph node metastases occur more frequently in extraaxillary basins due to aberrant drainage after initial breast cancer therapy. Supplementary nuclear medical imaging such as PET-CT or scintimammography may improve visualization of affected lymph nodes outside the axilla during relapse. For sentinel node biopsy, adding a SPECT-CT to planar lymphoscintigraphy increases the detection rate of sentinels, thus reducing the possibility of overlooking nodal metastases. 


\section{Operative management}

To summarize the literature on the operative management of clinically inapparent regional lymph nodes during breast cancer relapse, the following conclusions can be made: The choice of operation should be based on the axillary staging method at initial breast cancer disease. Patients with previous ALND should be spared a second systematic ALND as suggested by the German S3 guidelines and AGO recommendations. Lymphoscintigraphy may be performed to identify extraaxillary drainage basins.

Patients with previous SNB may receive a Re-SNB. This procedure has been proven as a feasible alternative option especially after initial BCS. In case of no visualization of the Re-sentinel node, omitting a secondary ALND may also be safe. In the study by Kaur et al. patients with unsuccessful Re-SNB did not receive a secondary ALND. At a median follow-up of 21.6 months, there were no lymph node recurrences [29]. In the SNARB study, the majority (75\%) of the patients with unsuccessful Re-SNB were spared an ALND. Yet the prognostic outcome was comparable to patients who received an ALND [45].

When mapping the Re-sentinel node, failure of lymphatic drainage was greatly associated with previous ALND and radiation as shown by the studies above. Both procedures are potentially damaging to lymphatic vessels. Whenever there is no sign of radioactive or blue dye migration from the breast to the adjacent regions, is it safe to assume that cancer cells in the breast are also not able to spread lymphatically, since the lymphatics are likely disrupted? The scenario of breast cancer cells being "trapped" locally may further encourage the omission of an ALND when the Resentinel node can't be visualized.

Another question concerns the rate of regional lymph node metastases and its prognostic value. As seen in the combined results above, the rate of metastases was as high as $17,9 \%$. However, in the SNARB study, the histological result of the re-SNB (benign, malign or unknown) did not influence the prognosis of the patients [44]. Does this mean, that an operative axillary staging including a Re-SNB can be completely abandoned, since its outcome did not matter? Are clinical and radiographic staging sufficient as long as they are inapparent? In the study by Ugras et al. there was no difference in the prognosis of patients whether they received a Re-SNB or no axillary surgery at all [47].

A possible explanation is that, rather than the radical surgical removal of regional nodes, the use of adjuvant therapy may have a larger prognostic impact in the recurrent setting of breast cancer. This has been demonstrated in the CALOR trial. Patients with breast cancer recurrence treated with adjuvant chemotherapy had a significantly longer disease-free survival and breast-cancer free interval compared to patients without chemotherapy. In a multivariable proportional hazards model, the location of the recurrence (i.e. in the regional lymph nodes) did not affect the patient's outcome, whereas the interval to first surgery and tumor subtype were identified as independent prognostic factors [48].

Furthermore, considering the historical development of surgical breast cancer treatment, it has been proven that doing more is not always better. In the last decades, the operating techniques had shifted from radical mastectomies and ALNDs for all patients to breast-conserving surgery and SNB whenever the clinical indication allows. This resulted in a nowadays substantially lower morbidity in breast cancer surgery without risking a higher mortality. One of the most burdensome treatment-related conditions is the development of lymphedemas. It heavily impairs quality of life, since there is only symptomatic treatment but no cure. The risk of developing lymphedemas is significantly higher after ALND than SNB [49]. Especially at breast cancer recurrence, when scarring in the lymphatics has been formed due to former operation and sometimes additional radiation, there may be an even increased risk of lymphedema development when performing additional axillary surgery. With this aspect in mind, the choice of the lymph node staging method and its radicality should be chosen even more cautiously in the recurrent setting.

In the end, uncertainties remain as all literature on the axillary staging procedure using the Re-SNB in recurrent breast cancer are retrospective analyses. As of now, there is no published randomized controlled study which compares the outcome of recurrent breast cancer patients after a Re-SNB vs. an ALND vs. no axillary surgery. To give definite recommendations for the clinical decision-making, this specific question should be further explored through prospective studies in the future.

Supplementary Information The online version contains supplementary material available at https://doi.org/10.1007/s00404-021-06352-9.

Author contributions IJ-B had the idea for the article. IG performed the literature search, data analysis and drafted and revised the manuscript. TE critically reviewed and revised the manuscript.

Funding Open Access funding enabled and organized by Projekt DEAL.

Availability of data and material Literature review in Pubmed, AGO recommendations, $\mathrm{NCCN}$ guidelines.

Code availability Not applicable.

\section{Declarations}

Conflict of interest The authors did not receive support from any organization for the submitted work. The authors certify that they have no affiliations with or involvement in any organization or entity with any financial interest or non-financial interest in the subject matter or materials discussed in this manuscript. 
Ethical approval Not applicable.

Consent to participate Not applicable.

Consent for publication Not applicable.

Open Access This article is licensed under a Creative Commons Attribution 4.0 International License, which permits use, sharing, adaptation, distribution and reproduction in any medium or format, as long as you give appropriate credit to the original author(s) and the source, provide a link to the Creative Commons licence, and indicate if changes were made. The images or other third party material in this article are included in the article's Creative Commons licence, unless indicated otherwise in a credit line to the material. If material is not included in the article's Creative Commons licence and your intended use is not permitted by statutory regulation or exceeds the permitted use, you will need to obtain permission directly from the copyright holder. To view a copy of this licence, visit http://creativecommons.org/licenses/by/4.0/.

\section{References}

1. Anderson SJ, Wapnir I, Dignam JJ, Fisher B, Mamounas EP, Jeong J-H, Geyer CE Jr, Wickerham DL, Costantino JP, Wolmark N (2009) Prognosis after ipsilateral breast tumor recurrence and locoregional recurrences in patients treated by breast-conserving therapy in five National Surgical Adjuvant Breast and Bowel Project protocols of node-negative breast cancer. J Clin Oncol 27(15):2466-2473. https://doi.org/10.1200/JCO.2008.19.8424

2. Harris EE, Hwang WT, Seyednejad F, Solin LJ (2003) Prognosis after regional lymph node recurrence in patients with stage I-II breast carcinoma treated with breast conservation therapy. Cancer 98(10):2144-2151. https://doi.org/10.1002/cncr.11767

3. Montagna E, Bagnardi V, Rotmensz N, Viale G, Renne G, Cancello G, Balduzzi A, Scarano E, Veronesi P, Luini A, Zurrida S, Monti S, Mastropasqua MG, Bottiglieri L, Goldhirsch A, Colleoni M (2012) Breast cancer subtypes and outcome after local and regional relapse. Ann Oncol 23(2):324-331. https://doi.org/10. 1093/annonc/mdr129

4. Lee MY, Chang WJ, Kim HS, Lee JY, Lim SH, Lee JE, Kim SW, Nam SJ, Ahn JS, Im YH, Park YH (2016) Clinicopathological features and prognostic factors affecting survival outcomes in isolated locoregional recurrence of breast cancer: single-institutional series. PLoS ONE 11(9):e0163254. https://doi.org/10.1371/journ al.pone. 0163254

5. Fowble B, Solin LJ, Schultz DJ, Goodman RL (1989) Frequency, sites of relapse, and outcome of regional node failures following conservative surgery and radiation for early breast cancer. Int $\mathrm{J}$ Radiat Oncol Biol Phys 17(4):703-710. https://doi.org/10.1016/ 0360-3016(89)90055-2

6. Recht A, Pierce SM, Abner A, Vicini F, Osteen RT, Love SM, Silver B, Harris JR (1991) Regional nodal failure after conservative surgery and radiotherapy for early-stage breast carcinoma. $\mathrm{J}$ Clin Oncol 9(6):988-996. https://doi.org/10.1200/jco.1991.9.6. 988

7. Wapnir IL, Anderson SJ, Mamounas EP, Geyer CE Jr, Jeong JH, Tan-Chiu E, Fisher B, Wolmark N (2006) Prognosis after ipsilateral breast tumor recurrence and locoregional recurrences in five National Surgical Adjuvant Breast and Bowel Project node-positive adjuvant breast cancer trials. J Clin Oncol 24(13):2028-2037. https://doi.org/10.1200/jco.2005.04.3273

8. Diepstraten SC, Sever AR, Buckens CF, Veldhuis WB, van Dalen T, van den Bosch MA, Mali WP, Verkooijen HM (2014) Value of preoperative ultrasound-guided axillary lymph node biopsy for preventing completion axillary lymph node dissection in breast cancer: a systematic review and meta-analysis. Ann Surg Oncol 21(1):51-59. https://doi.org/10.1245/s10434-013-3229-6

9. Houssami N, Ciatto S, Turner RM, Cody HS 3rd, Macaskill P (2011) Preoperative ultrasound-guided needle biopsy of axillary nodes in invasive breast cancer: meta-analysis of its accuracy and utility in staging the axilla. Ann Surg 254(2):243-251. https://doi. org/10.1097/SLA.0b013e31821f1564

10. Schipper RJ, van Roozendaal LM, de Vries B, Pijnappel RM, Beets-Tan RG, Lobbes MB, Smidt ML (2013) Axillary ultrasound for preoperative nodal staging in breast cancer patients: is it of added value? Breast (Edinburgh, Scotland) 22(6):1108-1113. https://doi.org/10.1016/j.breast.2013.09.002

11. Moon HJ, Kim MJ, Kim EK, Park BW, Youk JH, Kwak JY, Sohn J, Kim SI (2009) US surveillance of regional lymph node recurrence after breast cancer surgery. Radiology 252(3):673-681. https://doi.org/10.1148/radiol.2523081977

12. Cooper KL, Meng Y, Harnan S, Ward SE, Fitzgerald P, Papaioannou D, Wyld L, Ingram C, Wilkinson ID, Lorenz E (2011) Positron emission tomography (PET) and magnetic resonance imaging (MRI) for the assessment of axillary lymph node metastases in early breast cancer: systematic review and economic evaluation. Health Technol Assess (Winchester, England) 15(4):iii-134. https://doi.org/10.3310/hta15040

13. van Nijnatten TJA, Ploumen EH, Schipper RJ, Goorts B, Andriessen EH, Vanwetswinkel S, Schavemaker M, Nelemans P, de Vries B, Beets-Tan RGH, Smidt ML, Lobbes MBI (2016) Routine use of standard breast MRI compared to axillary ultrasound for differentiating between no, limited and advanced axillary nodal disease in newly diagnosed breast cancer patients. Eur J Radiol 85(12):2288-2294. https://doi.org/10.1016/j.ejrad.2016.10.030

14. DeSelm C, Yang TJ, Cahlon O, Tisnado J, Khan A, Gillespie E, Powell S, Ho A (2019) A 3-dimensional mapping analysis of regional nodal recurrences in breast cancer. Int $\mathbf{J}$ Radiat Oncol Biol Phys 103(3):583-591. https://doi.org/10.1016/j.ijrobp.2018. 10.021

15. Abo-Sheisha DM, Badawy ME (2014) The diagnostic value of $\mathrm{PET} / \mathrm{CT}$ in recurrence and distant metastasis in breast cancer patients and impact on disease free survival. Egyptian J Radiol Nuclear Med 45(4):1317-1324. https://doi.org/10.1016/j.ejrnm. 2014.07.006

16. Fuster D, Duch J, Paredes P, Velasco M, Muñoz M, Santamaría G, Fontanillas M, Pons F (2008) Preoperative staging of large primary breast cancer with [18F]Fluorodeoxyglucose positron emission tomography/computed tomography compared with conventional imaging procedures. J Clin Oncol 26(29):4746-4751. https://doi.org/10.1200/jco.2008.17.1496

17. Segaert I, Mottaghy F, Ceyssens S, De Wever W, Stroobants S, Van Ongeval C, Van Limbergen E, Wildiers H, Paridaens R, Vergote I, Christiaens MR, Neven P (2010) Additional value of PET$\mathrm{CT}$ in staging of clinical stage IIB and III breast cancer. Breast J 16(6):617-624. https://doi.org/10.1111/j.1524-4741.2010.00987.x

18. Borm KJ, Voppichler J, Düsberg M, Oechsner M, Vag T, Weber W, Combs SE, Duma MN (2019) FDG/PET-CT-based lymph node atlas in breast cancer patients. Int J Radiat Oncol Biol Phys 103(3):574-582. https://doi.org/10.1016/j.ijrobp.2018.07.2025

19. Dirisamer A, Halpern BS, Flöry D, Wolf F, Beheshti M, Mayerhoefer ME, Langsteger W (2010) Integrated contrast-enhanced diagnostic whole-body PET/CT as a first-line restaging modality in patients with suspected metastatic recurrence of breast cancer. Eur J Radiol 73(2):294-299. https://doi.org/10.1016/j.ejrad.2008. 10.031

20. Schmidt GP, Baur-Melnyk A, Haug A, Heinemann V, Bauerfeind I, Reiser MF, Schoenberg SO (2008) Comprehensive imaging of tumor recurrence in breast cancer patients using whole-body MRI 
at 1.5 and 3T compared to FDG-PET-CT. Eur J Radiol 65(1):4758. https://doi.org/10.1016/j.ejrad.2007.10.021

21. Lam WW, Yang WT, Chan YL, Stewart IE, Metreweli C, King W (1996) Detection of axillary lymph node metastases in breast carcinoma by technetium-99m sestamibi breast scintigraphy, ultrasound and conventional mammography. Eur J Nucl Med 23(5):498-503. https://doi.org/10.1007/bf00833382

22. Bongers V, Perre C, de Hooge P (2004) The use of scintimammography for detecting the recurrence of loco-regional breast cancer: histopathologically proven results. Nucl Med Commun 25(2):145-149. https://doi.org/10.1097/00006231-20040 2000-00009

23. Kumar R, Zhuang H, Schnall M, Conant E, Damia S, Weinstein S, Chandra P, Czerniecki B, Alavi A (2006) FDG PET positive lymph nodes are highly predictive of metastasis in breast cancer. Nucl Med Commun 27(3):231-236. https://doi.org/10.1097/ 00006231-200603000-00005

24. van der Ploeg IMC, Nieweg OE, Kroon BBR, Rutgers EJT, BaasVrancken Peeters M-JTFD, Vogel WV, Hoefnagel CA, Valdés Olmos RA (2009) The yield of SPECT/CT for anatomical lymphatic mapping in patients with breast cancer. Eur J Nuclear Med Mol Imaging. 36(6):903-909

25. Uren RF, Howman-Giles R, Chung DKV, Spillane AJ, Noushi F, Gillett D, Gluch L, Mak C, West R, Briody J, Carmalt H (2012) SPECT/CT scans allow precise anatomical location of sentinel lymph nodes in breast cancer and redefine lymphatic drainage from the breast to the axilla. The Breast 21(4):480-486. https:// doi.org/10.1016/j.breast.2011.11.007

26. Karanlik H, Ozgur I, Kilic B, Fathalizadeh A, Sanli Y, Onder S, Saip P, Sen F, Gulluoglu BM (2016) Sentinel lymph node biopsy and aberrant lymphatic drainage in recurrent breast cancer: findings likely to change treatment decisions. J Surg Oncol 114(7):796-802. https://doi.org/10.1002/jso.24423

27. Roumen RM, Kuijt GP, Liem IH (2006) Lymphatic mapping and sentinel node harvesting in patients with recurrent breast cancer. Eur J Surg Oncol 32(10):1076-1081. https://doi.org/10.1016/j. ejso.2006.08.007

28. Matsumoto A, Jinno H, Nakamura T, Saito J, Takahashi M, Hayashida T, Kameyama K, Kitagawa Y (2015) Technical feasibility of sentinel lymph node biopsy in patients with ipsilateral breast tumor recurrence and previous axillary surgery. Int J Surg (London, England) 22:28-31. https://doi.org/10.1016/j.ijsu.2015. 07.709

29. Kaur P, Kiluk JV, Meade T, Ramos D, Koeppel W, Jara J, King J, Cox CE (2011) Sentinel lymph node biopsy in patients with previous ipsilateral complete axillary lymph node dissection. Ann Surg Oncol 18(3):727-732. https://doi.org/10.1245/s10434-010-1120-2

30. Koizumi M, Koyama M, Tada K, Nishimura S, Miyagi Y, Makita M, Yoshimoto M, Iwase T, Horii R, Akiyama F, Saga T (2008) The feasibility of sentinel node biopsy in the previously treated breast. Eur J Surg Oncol 34(4):365-368. https://doi.org/10.1016/j. ejso.2007.04.007

31. Schrenk P, Tausch C, Wayand W (2008) Lymphatic mapping in patients with primary or recurrent breast cancer following previous axillary surgery. Eur J Surg Oncol 34(8):851-856. https://doi. org/10.1016/j.ejso.2007.11.006

32. Intra $\mathrm{M}$, Trifirò $\mathrm{G}$, Galimberti $\mathrm{V}$, Gentilini $\mathrm{O}$, Rotmensz N, Veronesi P (2007) Second axillary sentinel node biopsy for ipsilateral breast tumour recurrence. Br J Surg 94(10):1216-1219. https:// doi.org/10.1002/bjs.5813

33. Sávolt Á, Cserni G, Lázár G, Maráz R, Kelemen P, Kovács E, Győrffy B, Udvarhelyi N, Vörös A, Ormándi K, Mátrai Z (2019) Sentinel lymph node biopsy following previous axillary surgery in recurrent breast cancer. Eur J Surg Oncol 45(10):1835-1838. https://doi.org/10.1016/j.ejso.2019.05.016
34. Tokmak H, Kaban K, Muslumanoglu M, Demirel M, Aktan S (2014) Management of sentinel node re-mapping in patients who have second or recurrent breast cancer and had previous axillary procedures. World J Surg Oncol 12:205. https://doi.org/10.1186/ 1477-7819-12-205

35. Vugts G, Maaskant-Braat AJ, Voogd AC, van Riet YE, Luiten EJ, Rutgers EJ, Rutten HJ, Roumen RM, Nieuwenhuijzen GA (2015) Repeat sentinel node biopsy should be considered in patients with locally recurrent breast cancer. Breast Cancer Res Treat 153(3):549-556. https://doi.org/10.1007/s10549-015-3571-4

36. Folli S, Falco G, Mingozzi M, Buggi F, Curcio A, Ferrari G, Taffurelli M, Regolo L, Nanni O (2016) Repeat sentinel lymph node biopsy in patients with ipsilateral recurrent breast cancer after breast-conserving therapy and negative sentinel lymph node biopsy: a prospective study. Minerva Chir 71(2):73-79

37. Uth CC, Christensen MH, Oldenbourg MH, Kjær C, Garne JP, Teilum D, Kroman N, Tvedskov TF (2015) Sentinel lymph node dissection in locally recurrent breast cancer. Ann Surg Oncol 22(8):2526-2531. https://doi.org/10.1245/s10434-014-4338-6

38. Port ER, Garcia-Etienne CA, Park J, Fey J, Borgen PI, Cody HS 3rd (2007) Reoperative sentinel lymph node biopsy: a new frontier in the management of ipsilateral breast tumor recurrence. Ann Surg Oncol 14(8):2209-2214. https://doi.org/10.1245/ s10434-006-9237-z

39. Yoon CI, Ahn SG, Kim D, Choi JE, Bae SJ, Cha CH, Park S, Jeong J (2020) Repeat sentinel lymph node biopsy for ipsilateral breast tumor recurrence after breast conserving surgery with sentinel lymph node biopsy: pooled analysis using data from a systematic review and two institutions. Front Oncol 10:518568. https://doi.org/10.3389/fonc.2020.518568

40. Derkx F, Maaskant-Braat AJ, van der Sangen MJ, Nieuwenhuijzen GA, van de Poll-Franse LV, Roumen RM, Voogd AC (2010) Staging and management of axillary lymph nodes in patients with local recurrence in the breast or chest wall after a previous negative sentinel node procedure. Eur J Surg Oncol 36(7):646-651. https:// doi.org/10.1016/j.ejso.2010.05.009

41. Biglia N, Bounous VE, Gallo M, Fuso L, Sgro LG, Maggiorotto F, Ponzone R (2018) Feasibility and oncological safety of sentinel node biopsy in breast cancer patients with a local recurrence. Breast (Edinburgh, Scotland) 41:8-13. https://doi.org/10.1016/j. breast.2018.06.004

42. Karam A, Stempel M, Cody HS 3rd, Port ER (2008) Reoperative sentinel lymph node biopsy after previous mastectomy. J Am Coll Surg 207(4):543-548. https://doi.org/10.1016/j.jamcollsurg.2008. 06.139

43. Cox CE, Furman BT, Kiluk JV, Jara J, Koeppel W, Meade T, White L, Dupont E, Allred N, Meyers M (2008) Use of reoperative sentinel lymph node biopsy in breast cancer patients. J Am Coll Surg 207(1):57-61. https://doi.org/10.1016/j.jamcollsurg. 2008.01.017

44. Poodt IGM, Vugts G, Schipper RJ, Roumen RMH, Rutten HJT, Maaskant-Braat AJG, Voogd AC, Nieuwenhuijzen GAP (2019) Prognostic impact of repeat sentinel lymph node biopsy in patients with ipsilateral breast tumour recurrence. Br J Surg 106(5):574585. https://doi.org/10.1002/bjs.11097

45. Poodt IGM, Walstra C, Vugts G, Maaskant-Braat AJG, Voogd AC, Schipper RJ, Nieuwenhuijzen GAP (2019) Low risk of development of a regional recurrence after an unsuccessful repeat sentinel lymph node biopsy in patients with ipsilateral breast tumor recurrence. Ann Surg Oncol 26(8):2417-2427. https://doi.org/10.1245/ s10434-019-07272-4

46. Jakub JW (2019) Sentinel lymph node biopsy for ipsilateral breast tumor recurrence, technically feasible but influence on oncologic outcomes yet to be completely defined. Ann Surg Oncol 26(8):2319-2321. https://doi.org/10.1245/s10434-019-07356-1 
47. Ugras S, Matsen C, Eaton A, Stempel M, Morrow M, Cody HS 3rd (2016) Reoperative sentinel lymph node biopsy is feasible for locally recurrent breast cancer, but is it worthwhile? Ann Surg Oncol 23(3):744-748. https://doi.org/10.1245/s10434-015-5003-4

48. Wapnir IL, Price KN, Anderson SJ, Robidoux A, Martín M, Nortier JWR, Paterson AHG, Rimawi MF, Láng I, Baena-Cañada JM, Thürlimann B, Mamounas EP, Geyer CE, Gelber S, Coates AS, Gelber RD, Rastogi P, Regan MM, Wolmark N, Aebi S (2018) Efficacy of chemotherapy for ER-negative and ER-positive isolated locoregional recurrence of breast cancer: final analysis of the CALOR trial. J Clin Oncol 36(11):1073-1079. https://doi.org/10. 1200/JCO.2017.76.5719

49. McLaughlin SA, Bagaria S, Gibson T, Arnold M, Diehl N, Crook J, Parker A, Nguyen J (2013) Trends in risk reduction practices for the prevention of lymphedema in the first 12 months after breast cancer surgery. J Am College Surgeons 216(3):380-389

50. Sato A, Sakai T, Iwase T, Kano F, Kimura K, Ogiya A, Koizumi M, Tanabe M, Horii R, Akiyama F, Ueno T, Ohno S (2019) Altered lymphatic drainage patterns in re-operative sentinel lymph node biopsy for ipsilateral breast tumor recurrence. Radiation Oncol (London, England) 14(1):159. https://doi.org/10.1186/ s13014-019-1367-0

51. Poodt IGM, Vugts G, Maaskant-Braat AJG, Schipper RJ, Voogd AC, Nieuwenhuijzen GAP (2018) Risk of regional recurrence after negative repeat sentinel lymph node biopsy in patients with ipsilateral breast tumor recurrence. Ann Surg Oncol 25(5):13121321. https://doi.org/10.1245/s10434-018-6384-y

52. Intra M, Viale G, Vila J, Grana CM, Toesca A, Gentilini O, Galimberti V, Veronesi P, Luini A, Rotmensz N, Bagnardi V, Mattar D, Colleoni M (2015) Second axillary sentinel lymph node biopsy for breast tumor recurrence: experience of the European institute of oncology. Ann Surg Oncol 22(7):2372-2377. https://doi.org/ 10.1245/s10434-014-4282-5

53. Tasevski R, Gogos AJ, Mann GB (2009) Reoperative sentinel lymph node biopsy in ipsilateral breast cancer relapse. Breast (Edinburgh, Scotland) 18(5):322-326. https://doi.org/10.1016/j. breast.2009.09.009
54. Axelsson CK, Jønsson PE (2008) Sentinel lymph node biopsy in operations for recurrent breast cancer. Eur J Surg Oncol 34(6):626-630. https://doi.org/10.1016/j.ejso.2007.09.004

55. Barone JL, Feldman SM, Estabrook A, Tartter PI, Rosenbaum Smith SM, Boolbol SK (2007) Reoperative sentinel lymph node biopsy in patients with locally recurrent breast cancer. Am J Surg 194(4):491-493. https://doi.org/10.1016/j.amjsurg.2007.07.011

56. Boughey JC, Ross MI, Babiera GV, Bedrosian I, Feig BW, Hwang RF, Kuerer HM, Hunt KK (2006) Sentinel lymph node surgery in locally recurrent breast cancer. Clin Breast Cancer 7(3):248-253. https://doi.org/10.3816/CBC.2006.n.037

57. Taback B, Nguyen P, Hansen N, Edwards GK, Conway K, Giuliano AE (2006) Sentinel lymph node biopsy for local recurrence of breast cancer after breast-conserving therapy. Ann Surg Oncol 13(8):1099-1104. https://doi.org/10.1245/aso.2006.08.026

58. Newman EA, Cimmino VM, Sabel MS, Diehl KM, Frey KA, Chang AE, Newman LA (2006) Lymphatic mapping and sentinel lymph node biopsy for patients with local recurrence after breastconservation therapy. Ann Surg Oncol 13(1):52-57. https://doi. org/10.1245/aso.2006.12.002

59. Dinan D, Nagle CE, Pettinga J (2005) Lymphatic mapping and sentinel node biopsy in women with an ipsilateral second breast carcinoma and a history of breast and axillary surgery. Am J Surg 190(4):614-617. https://doi.org/10.1016/j.amjsurg.2005.06.025

60. Sood A, Youssef IM, Heiba SI, El-Zeftawy H, Axelrod D, Seigel B, Mills C, Abdel-Dayem HM (2004) Alternative lymphatic pathway after previous axillary node dissection in recurrent/primary breast cancer. Clin Nucl Med 29(11):698-702. https://doi.org/10. 1097/00003072-200411000-00005

Publisher's Note Springer Nature remains neutral with regard to jurisdictional claims in published maps and institutional affiliations. 